УДК 322:528.1

DOI: $10.33764 / 2687-041 X-2021-1-65-71$

\title{
ОСНОВНЫЕ ПОНЯТИЯ И КЛАССИФИКАЦИЯ БЕСПИЛОТНЫХ АВИАЦИОННЫХ СИСТЕM
}

\section{Александр Александрович Антонов}

Сибирский государственный университет геосистем и технологий, 630108, Россия, г. Новосибирск, ул. Плахотного, 10, обучающийся, тел. (983)314-37-59, e-mail: al.antonov98@gmail.com

\section{Владислав Александрович Зазулин}

Сибирский государственный университет геосистем и технологий, 630108, Россия, г. Новосибирск, ул. Плахотного, 10, обучающийся, тел. (913)769-96-31, e-mail: zazulinvlad97@gmail.com

\section{Полина Евгеньевна Иваненко}

Сибирский государственный университет геосистем и технологий, 630108, Россия, г. Новосибирск, ул. Плахотного, 10, обучающийся, тел. (913)065-08-04, e-mail: polli-holli@mail.ru

В статье представлены основные понятия и классификация беспилотных авиационных систем и их составляющей.

Ключевые слова: беспилотные авиационные системы, фотограмметрический метод, беспилотный летательный аппарат

\section{BASIC CONCEPTS AND CLASSIFICATION OF UNMANNED AERIAL SYSTEMS}

\section{Alexandr A. Antonov}

Siberian State University of Geosystems and Technologies, 10, Plakhotnogo St., Novosibirsk, 630108, Russia, Student, phone: (983)314-37-59, e-mail: al.antonov98@gmail.com

\section{Vladislav A. Zazulin}

Siberian State University of Geosystems and Technologies, 10, Plakhotnogo St., Novosibirsk, 630108, Russia, Student, phone: (913)769-96-31, e-mail: zazulinvlad97@gmail.com

\section{Polina E. Ivanenko}

Siberian State University of Geosystems and Technologies, 10, Plakhotnogo St., Novosibirsk, 630108, Russia, Student, phone: (913)065-08-04, e-mail: polli-holli@mail.ru

The article presents the basic concepts and classification of unmanned aerial systems and their components.

Keywords: unmanned aerial systems, photogrammetric method, unmanned aerial vehicle

Сфера земельно-имущественных отношений постоянно претерпевает прогрессивные изменения. Так в последнее время активное развитие получил 3Dкадастр. Постоянное совершенствование системы сбора и хранения данных, учета и обработки информации, а также появление современных технологий 
выполнения геодезических измерений в совокупности с доступным программным обеспечением, позволяют выполнять геодезические работы, связанные с объектами недвижимости, в кратчайшие сроки.

В тоже время, одной из наиболее актуальных проблем последнего десятилетия, которая замедляет процесс выполнения кадастровых работ в отношении земельных участков, является отсутствие единой цифровой картографической основы (ЕЦКО), а также отсутствие полноценного реестра объектов недвижимости.

Исходя из этого, целью данного исследования является изучение основных понятий беспилотных авиационных систем (БАС), и их классификация.

На сегодняшний день в законодательстве РФ не зафиксировано определение БАС и БПЛА. В рамках данного исследования предлагается авторское описание данных терминов.

БАС - представляют собой совокупность беспилотных авиационных комплексов (БАК), включающих в себя материально-техническое обеспечение, программное обеспечение, документацию, технический персонал, функциональные средства и средства для интеграции с другими системами (рис. 1).

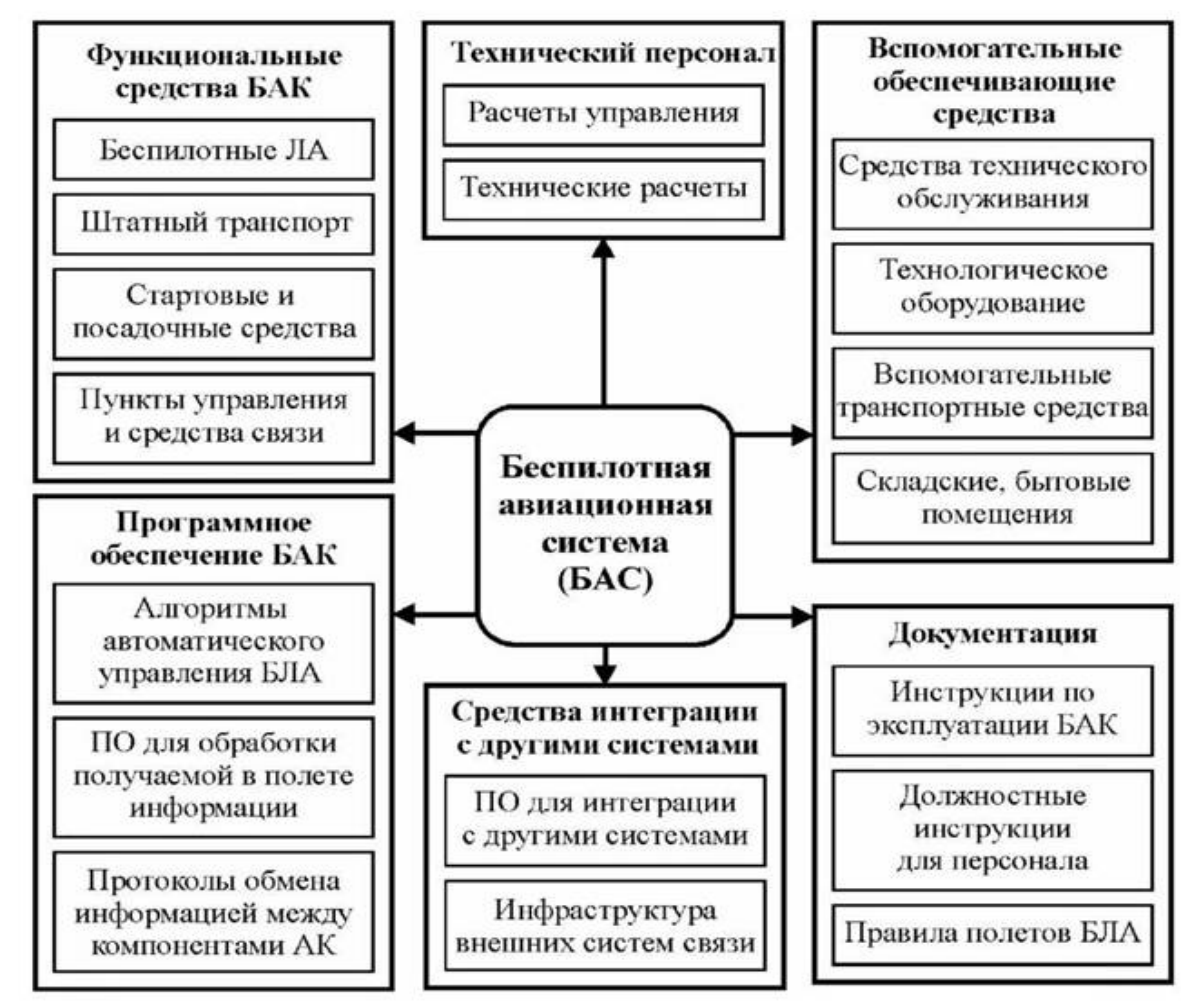

Рис. 1. Структура БАС

БПЛА - воздушное судно, не имеющее пилота, главным преимуществом которого является возможность управления с любой точки земли, с борта другого воздушного судна или космического спутника. 
Связь между воздушным судном и оператором осуществляется посредством передачи данных по защищенному каналу связи. Данные о своем местоположении БПЛА получает от системы спутников глобального позиционирования (GPS) (рис. 2). Данные полученные от GPS позволяют определять координаты центра фотографирования снимка, в геоцентрической системе координат $[1,2]$. Для возможности применения данных АФС для целей ведения ЕГРН, необходимы точки сети ПВО в локальной системе координат. Что является основным способом привязки к местности.

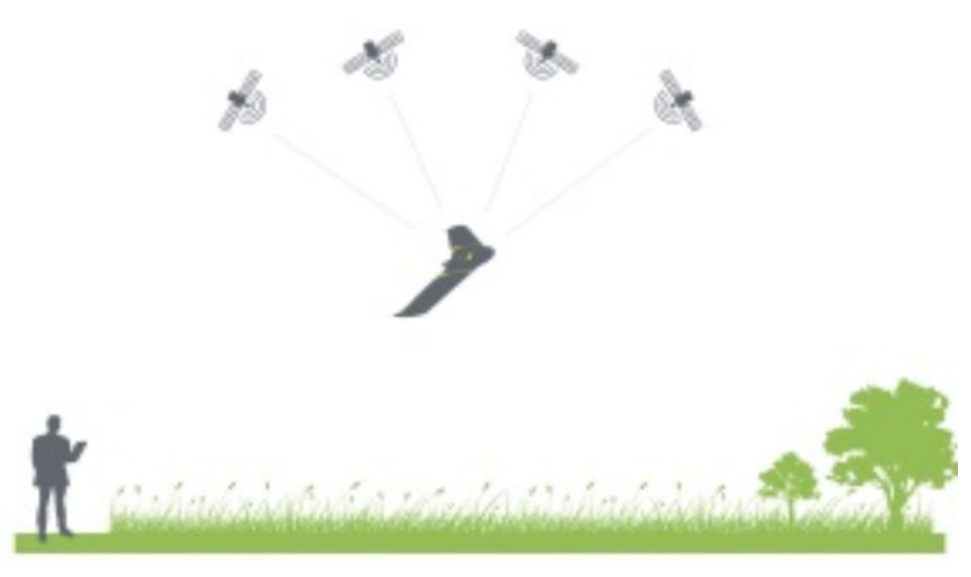

Рис. 2. Связь между спутниками GPS и БПЛА

Однако не всегда есть возможность разместить на фотографируемой территории точки сети ПВО и произвести их измерения в локальной системе координат, исходя из этого, в последние несколько лет активное развитие получило применение Real Time Kinematic (RTK) и Post Processed Kinematic (РРК) режимов.

При АФС в режиме RTK, БПЛА обменивается данными с базовой станцией через устройство контролирующее полет (рис. 3). Связь устройства и базовой станции осуществляется через Wi-Fi или GSM канал связи [1].

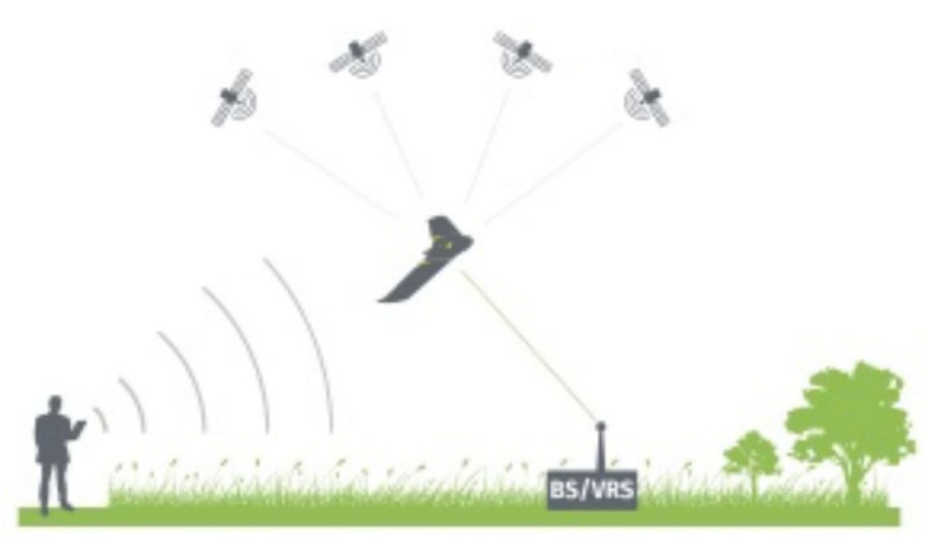

Рис. 3. Связь между спутниками GPS, БПЛА и базовой станцией 
Однако необходимо учитывать, что координаты базовой станции должны быть определенны с высокой точностью. В качестве базовой станции на территории Новосибирской области возможно использование сети спутниковых дифференциальных геодезических станций.

Материалы полученные в результате АЭС в любом из режимов служат исходными данными для стереофотограмметрической обработки.

Область применения БПЛА достаточно широка: транспортировка, доставка грузов, аэрофотосъемка местности и объектов капитального строительства, мониторинг территории, стратегическое назначение и оборона государства. Общая классификация БПЛА представлена на рис. 4.

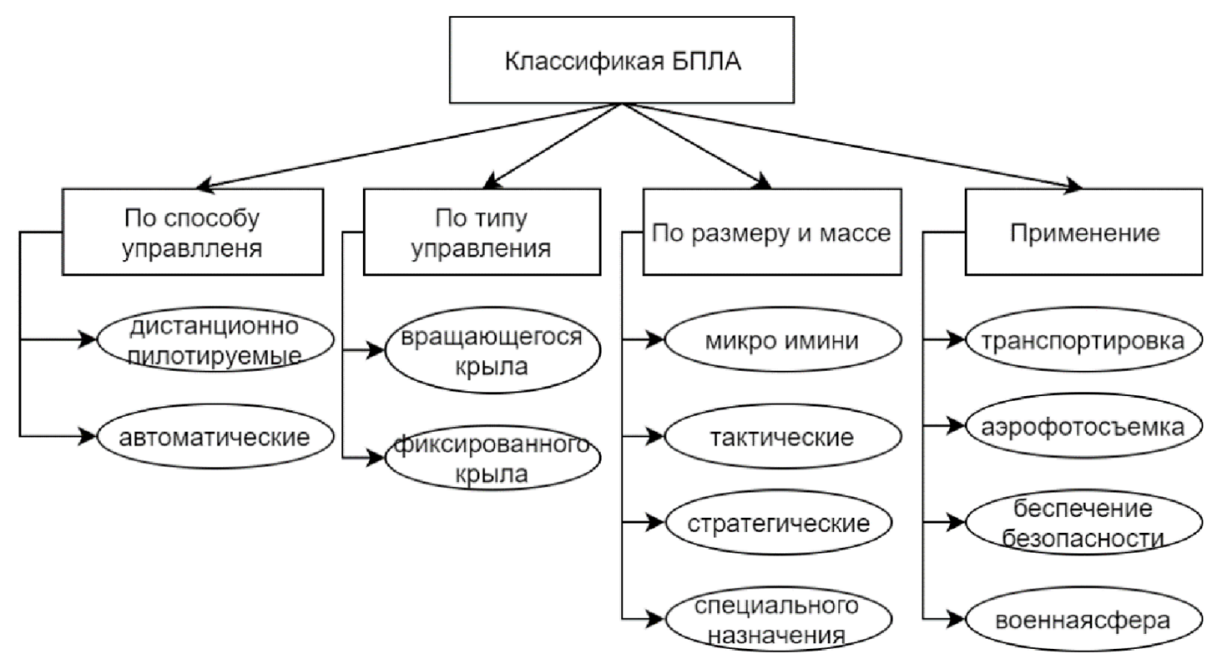

Рис. 4. Общая классификация БПЛА

Однако на сегодняшний день большое распространение получила универсальная классификация по взлетной массе БПЛА, представленная в таблице.

Универсальная классификация БПЛА

\begin{tabular}{|l|l|l|}
\hline \multicolumn{1}{|c|}{ Класс БПЛА } & \multicolumn{1}{|c|}{$\begin{array}{c}\text { Взлетная } \\
\text { масса, кг }\end{array}$} & \multicolumn{1}{|c|}{$\begin{array}{c}\text { Дальность } \\
\text { действия, км }\end{array}$} \\
\hline \multicolumn{1}{|c|}{1} & \multicolumn{1}{|c|}{2} & \multicolumn{1}{c|}{3} \\
\hline 1 Микро- и мини-БПЛА ближнего радиуса действия & до 5 & до 25-40 \\
\hline 2 Легкие БПЛА малого радиуса действия & $5-50$ & $10-70$ \\
\hline 3 Легкие БПЛА среднего радиуса действия & $50-100$ & $70-150(250)$ \\
\hline 4 Средние БПЛА & $100-300$ & $150-1000$ \\
\hline 5 Средне-тяжелые БПЛА & $300-500$ & $70-300$ \\
\hline 6 Тяжелые БПЛА среднего радиуса действия & более 500 & $70-300$ \\
\hline 7 Тяжелые БПЛА большой продолжительности полета & более 1500 & около 1500 \\
\hline 8 Беспилотные боевые самолеты & Более 500 & около 1500 \\
\hline
\end{tabular}

На городских территориях плотной застройки, по площади сопоставимой с размерами кадастрового квартала, рационально использовать БПЛА вращающегося крыла (рис. 5), так как для совершения взлета и посадки дрона требует- 
ся площадка площадью не более 1-2 квадратных метров [8-10]. Однако стоит учитывать, что полетное время у БПЛА вращающегося крыла значительно меньше чем у БПЛА фиксированного крыла.

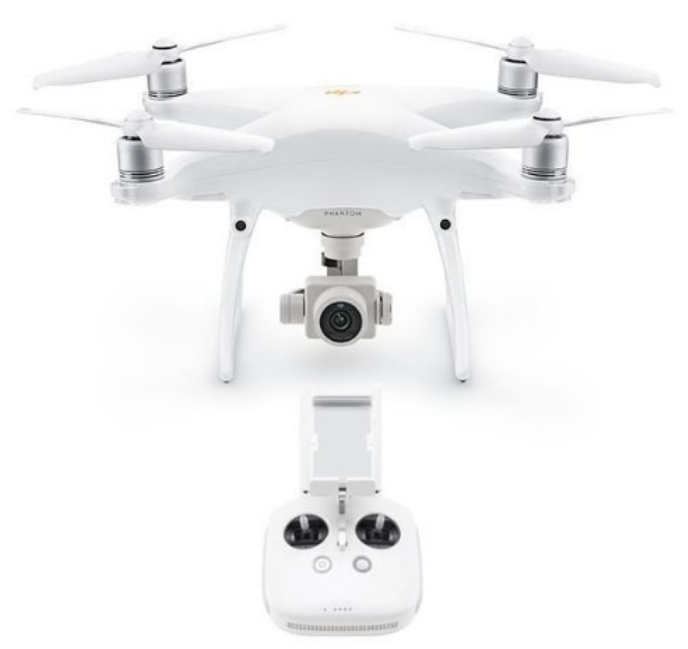

Рис. 5. БПЛА вращающегося крыла

Для совершения полетов над территорией, сопоставимой с размерами нескольких кадастровых кварталов и более, рациональным становится использование БПЛА фиксированного крыла (рисунок 6) [4, 6, 7]. Такие БПЛА обладают возможностью более долгой съемки, чем БПЛА вращающегося крыла. Однако стоит принять во внимание, что для взлета и посадки такого БПЛА требуется специализированное оборудование и открытая территория.

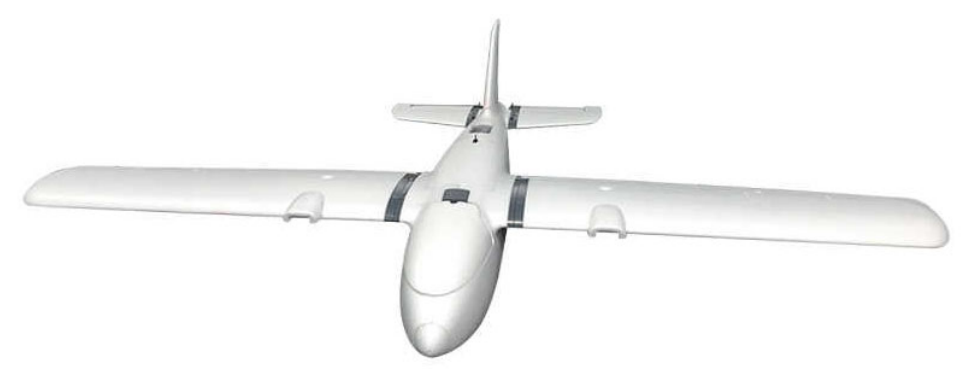

Рис. 6. БПЛА фиксированного крыла

Полет на БПЛА осуществляется в одном из двух режимов, автоматическом или ручном. Для совершения полета в автоматическом режиме оператор перед началом полета проектирует полетное задание в программном обеспечении, таком как, Pix 4D Capture, Dronedeploy, установленным на оборудование для 
управления полетом БПЛА. Оператор устанавливает процент необходимого продольного и поперечного перекрытия снимков, угол наклона камеры и высоту полета. После нажатия кнопки старт, весь полет происходит в автономном режиме, без участия человека $[1,12]$.

При полете в ручном режиме, все операции по управлению дроном, углом наклона камеры, моментом фотографирования, выполняются оператором в режиме реального времени, что, в свою очередь, требует высокой концентрации внимания и опыта полетов на БПЛА.

Стоит отметить, что любой из режимов съемки, дает необходимые материалы для дальнейшей работы. Однако, использование автоматического режима формирует наиболее стабильный процесс аэрофотографирования в совокупности с соблюдением единого процента перекрытия снимков.

Несмотря на всю сложность технических задач и большое число пока еще не решенных организационных и регулятивных проблем, гражданское применение БПЛА, вне всякого сомнения, является переходом на следующую технологическую ступень развития многих отраслей. Их применение в различных сферах деятельности позволяет сократить время, повысить качество и точность получаемых данных.

\section{БИБЛИОГРАФИЧЕСКИЙ СПИСОК}

1. Алябьев, А. А. Фотограмметрический метод в кадастровых работах: цифровые стереомодели и ортофотопланы [Текст] / А. А. Алябьев, К. А. Литвинцев, Е. А. Кобзева // Геопрофи. - 2018. - № 2. - С. 4-8.

2. Антипов, И. Т. Об использовании цифровых средне- и малоформатных камер для аэрофотосъемки [Текст] / И. Т. Антипов, Е. А. Кобзева // Геодезия и картография. - 2013. № 11. - С. 29-34.

3. Арбузов, С. А. Реализация практико-ориентированного обучения посредством научно-образовательного и производственного центра беспилотных авиационных систем (НОПЦ БАС) СГУГиТ [Текст] / С. А. Арбузов, М. А. Петрова, О. А. Опритова // АКТУАЛЬНЫЕ ВОПРОСЫ ОБРАЗОВАНИЯ. Инновационные подходы в образовании. Междунар. науч.метод. конф. : сб. материалов в 2 ч. (Новосибирск, 23-27 января 2017 г.). - Новосибирск : СГУГиТ, 2017. Ч. 1. - С. 210-214.

4. Воздушный кодекс Российской ФедерацииФедерации [Электронный ресурс]: Федеральный закон от 19.03.1997 N 60-Ф3 // СПС «КонсультантПлюс».

5. Гебгарт, Я. И. Некоторые вопросы измерения снимков [Текст] / Я. И. Гебгарт, У. Д. Ниязгулов, А. А. Гебгарт // Геодезия и картография. - 2005. - № 2. - С. 24-25.

6. ГКИНП (ГНТА)-02-036-02. Инструкция по фотограмметрическим работам при создании цифровых топографических карт и планов [Текст]. - М. : ЦНИИГАиК, 2002. - 100 с.

7. ГКИНП-09-32-80. Основные положения по аэрофотосъемке, выполняемой для создания и обновления топографических карт и планов [Текст]. - М. : Недра, 1982. - 17 с.

8. ГКИНП 02-121-79. Руководство по дешифрированию аэроснимков планов масштабов $1: 2000$ и $1: 5000$ [Текст]. - М. : ЦНИИГАиК, 198 с.

9. Об утверждении требований к точности и методам определения координат характерных точек границ земельного участка, требований к точности и методам определения координат характерных точек контура здания, сооружения или объекта незавершенного строительства на земельном участке, а также требований к определению площади здания, соору- 
жения и помещения : приказ Минэкономразвития России от 01.03.2016 № 90 [Электронный ресурс]. - Доступ из справ.- правовой системы «КонсультантПлюс».

10. "Об утверждении Федеральных правил использования воздушного пространства Российской Федерации" [Электронный ресурс]: Постановление Правительства РФ от 11.03.2010 N 138 (ред. от 03.02.2020) // СПС «КонсультантПлюс».

11. Хлебникова, Т. А. Экспериментальные исследования точности построения фотограмметрической модели по материалам БПЛА [Текст] / Т. А. Хлебникова, О. А. Опритова, С. М. Аубакирова // Интерэкспо ГЕО-Сибирь. XIV Междунар. науч. конгр. : Междунар. науч. конф. «Дистанционные методы зондирования Земли и фотограмметрия, мониторинг окружающей среды, геоэкология» : сб. материалов в 2 т. (Новосибирск, 25-27 апреля 2018 г.). - Новосибирск : СГУГиТ, 2018. Т. 1. - С. 32-37.

12. Цветков, В. Я. Автоматизированные фотограмметрические методы восстановления архитектурных объектов [Текст] : дис. ... д-ра техн. наук : 05.24.02 : защищена 18.11.1994 / Цветков Владимир Яковлевич. - М., 1994. - 323 с.

(C) А. А. Антонов, В. А. Зазулин, П. Е. Иваненко, 2021 